\title{
Disease activity assessment of rheumatic diseases during pregnancy: a comprehensive review of indices used in clinical studies
}

Laura Andreoli ${ }^{\mathrm{a}, *, 1}$, Maria Chiara Gerardi ${ }^{\mathrm{a}, 1}$, Melissa Fernandes ${ }^{\mathrm{b}, 1}$, Alessandra Bortoluzi Silvia Bellando-Randone ${ }^{\mathrm{d}}$, Antonio Brucato ${ }^{\mathrm{e}}$, Roberto Caporali ${ }^{\mathrm{f}}$, Cecilia Beatrice Chighizola ${ }^{\mathrm{g}}$, Maria Sole Chimenti ${ }^{\mathrm{h}}$, Paola Conigliaro ${ }^{\mathrm{h}}$, Maurizio Cutolo ${ }^{\mathrm{i}}$, Maria Stefania Cutro ${ }^{\mathrm{j}}$, Salvatore D’Angelo ${ }^{\mathrm{j}}$, Andrea Doria ${ }^{\mathrm{k}}$, Elena Elefante ${ }^{\mathrm{l}}$, Micaela Fredi ${ }^{\mathrm{a}}$, Mauro Galeazzi ${ }^{\mathrm{m}}$, Maria Gerosa $^{n}$, Marcello Govoni ${ }^{\mathrm{c}}$, Annamaria Iuliano ${ }^{\circ}$, Maddalena Larosa $^{\mathrm{k}}$, Maria Grazia Lazzaroni ${ }^{\mathrm{a}}$, Marco Matucci-Cerinic ${ }^{\mathrm{d}}$, Marianna Meroni ${ }^{\mathrm{p}}$, Pier Luigi Meroni ${ }^{\mathrm{q}}$, Marta Mosca ${ }^{1}$, Massimo Patanè ${ }^{\mathrm{i}}$, Giulia Pazzola ${ }^{\mathrm{r}}$, Monica Pendolino ${ }^{\mathrm{i}}$, Roberto Perricone ${ }^{\mathrm{h}}$, Véronique Ramoni ${ }^{\mathrm{f}}$, Carlo Salvarani ${ }^{\mathrm{r}}$, Gian Domenico Sebastiani ${ }^{\mathrm{o}}$, Carlo Selmi ${ }^{\mathrm{p}, \mathrm{s}}$, Francesca Romana Spinelli ${ }^{\mathrm{t}}$, Guido Valesini ${ }^{\mathrm{t}}$, Carlo Alberto Scirè ${ }^{\mathrm{c}, \mathrm{u}, 2}$, Angela Tincani ${ }^{\mathrm{a}, 1,2}$

\footnotetext{
${ }^{a}$ Rheumatology and Clinical Immunology, Spedali Civili and Department of Clinical and Experimental Sciences, University of Brescia, Brescia, Italy

${ }^{\mathrm{b}}$ Department of Internal Medicine, Autoimmune Disease Unit, Hospital Curry Cabral/Centro Hospitalar Lisboa Central, Lisbon, Portugal

${ }^{\mathrm{c}}$ Department of Medical Sciences, Rheumatology Unit, S. Anna Hospital, University of Ferrara, Ferrara, Italy

${ }^{\mathrm{d}}$ Department of Experimental and Clinical Medicine, Division of Rheumatology AOUC, University of Florence, Florence, Italy

${ }^{\mathrm{e}}$ Internal Medicine Division, Ospedale Papa Giovanni XXIII, Bergamo, Italy

${ }^{\mathrm{f}}$ Division of Rheumatology, University and IRCCS Policlinico S. Matteo Foundation, Pavia, Italy

${ }^{\mathrm{g}}$ Department of Clinical Sciences and Community Health, Experimental Laboratory of Immunological and Rheumatologic Researches, IRCCS Istituto Auxologico Italiano, University of Milan, Cusano Milanino, Milan, Italy

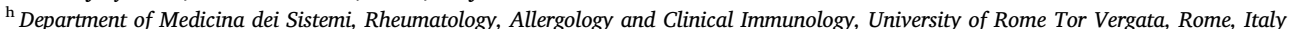

i Department of Internal Medicine, Research Laboratory and Academic Division of Clinical Rheumatology, IRCCS San Martino Polyclinic Hospital, University of Genova, Genova, Italy

${ }^{\mathrm{j}}$ Rheumatology Department of Lucania, San Carlo Hospital of Potenza, Madonna delle Grazie of Matera, Matera, Italy

${ }^{\mathrm{k}}$ Division of Rheumatology, University of Padova, Padova, Italy

${ }^{1}$ Department of Clinical and Experimental Medicine, Rheumatology Unit, University of Pisa, Pisa, Italy

${ }^{\mathrm{m}}$ Rheumatology Unit, Department of Medical Sciences, Surgery and Neurosciences, Azienda ospedaliera Universitaria Senese, Siena, Italy

${ }^{n}$ Department of Clinical Sciences and Community Health, Department of Rheumatology, ASST Istituto Gaetano Pini \& CTO, University of Milan, Milan, Italy

${ }^{\circ}$ Rheumatology Unit, San Camillo Hospital, Rome, Italy

${ }^{\mathrm{p}}$ Rheumatology \& Clinical Immunology, Humanitas Research Hospital, Rozzano, Milan, Italy

${ }^{\mathrm{q}}$ Experimental Laboratory of Immunological and Rheumatologic Researches, IRCCS Istituto Auxologico Italiano, Cusano Milanino, Milan, Italy

${ }^{\mathrm{r}}$ Rheumatology Unit, Azienda USL-IRCCS di Reggio Emilia, Università di Modena e Reggio Emilia, Modena, Italy

${ }^{s}$ BIOMETRA Department, University of Milan, Milan, Italy

${ }^{\mathrm{t}}$ Dipartimento di Medicina Interna e Specialità Mediche-Reumatologia, Sapienza University of Rome, Rome, Italy

${ }^{\mathrm{u}}$ Epidemiology Unit, Italian Society for Rheumatology (SIR), Milan, Italy
}

\section{A R T I C L E I N F O}

\section{Keywords:}

Pregnancy

Activity indices

Rheumatoid arthritis

Spondyloarthritis

Systemic lupus erythematosus

Autoimmune diseases

Vasculitis

\begin{abstract}
A B S T R A C T
Pregnancy requires a special management in women with inflammatory rheumatic diseases (RDs), with the aim of controlling maternal disease activity and avoiding fetal complications. Despite the heterogeneous course of RDs during pregnancy, their impact on pregnancy largely relates to the extent of active inflammation at the time of conception. Therefore, accurate evaluation of disease activity is crucial for the best management of pregnant patients. Nevertheless, there are limitations in using conventional measures of disease activity in pregnancy, as some items included in these instruments can be biased by symptoms or by physiological changes related to pregnancy and the pregnancy itself may influence laboratory parameters used to assess disease activity. This article aims to summarize the current literature about the available instruments to measure disease activity
\end{abstract}

\footnotetext{
* Corresponding author at: Department of Clinical and Experimental Sciences, University of Brescia, Brescia, Italy.

E-mail address: laura.andreoli@unibs.it (L. Andreoli).

${ }^{1}$ These authors contributed equally to this work.

${ }^{2}$ These authors share senior authorship.
} 
during pregnancy in RDs. Systemic lupus erythematosus is the only disease with instruments that have been modified to account for several adaptations which might interfere with the attribution of signs or symptoms to disease activity during pregnancy. No modified-pregnancy indices exist for women affected by other RDs, but standard indices have been applied to pregnant patients.

The current body of knowledge shows that the physiologic changes that occur during pregnancy need to be either adapted from existing instruments or developed to improve the management of pregnant women with RDs. Standardized instruments to assess disease activity during pregnancy would be helpful not only for clinical practice but also for research purposes.

\section{Introduction}

Rheumatic diseases (RDs) often affect women during childbearing age. Planning a family is now a reality for these women, thanks to earlier diagnosis and improved management of RDs. Pregnancy is a delicate period that needs a special management to control the maternal disease and to avoid complications for both the mother and the fetus. The management of RDs during pregnancy should aim at minimizing the effects of maternal disease on pregnancy outcome.

Rheumatoid arthritis (RA) and chronic inflammatory arthritis, such as polyarticular juvenile idiopathic arthritis (JIA), tend to improve spontaneously during pregnancy in the majority of patients [1], even though less frequently than described in the past [2]. Spondyloarthritis (SpA) tend to be stable or to get worse during pregnancy, even though the available literature is scarce [1]. Systemic lupus erythematosus (SLE) can flare up to $50 \%$ of pregnancies, including a major organ involvement in nearly $25 \%$ of the cases [1]. The effect of other connective tissue diseases (CTD) on pregnancy or vice versa has been less investigated. A special consideration should be given to anti-phospholipid syndrome (APS) because one of its main clinical manifestations are pregnancy complications. Pregnancy does not seem to worsen the activity of systemic vasculitis, but a disease flare during pregnancy can lead to severe complications [3].

Active disease or flares during pregnancy can negatively impact fetal health and pregnancy outcome [4]. Therefore, accurate evaluation of disease activity is crucial for the best management of these patients. However, there are limitations in using conventional measures of disease activity in pregnancy, as some items from these instruments can be biased by symptoms or by physiological changes related to pregnancy and pregnancy itself may influence laboratory parameters [5]. In particular, some laboratory investigations have to be interpreted with caution: mild anemia, mild thrombocytopenia, proteinuria, and increased erythrocyte sedimentation rate (ESR) are common during pregnancy. Complement levels become less informative with the increase in levels during normal pregnancy and renal function should be interpreted considering the physiological increased plasma volume and glomerular filtration rate. Pregnancy can cause skin manifestations, mild knee effusion and low back pain that can interfere with the evaluation of disease activity.

Most of the studies on this subject have focused on SLE and RA. However, different instruments and definitions of remission or flares were used, making it difficult to compare different cohorts. It clearly emerges that valid measures of disease activity during gestation are of pivotal importance. The paucity of documentation and the lack of standardization make this a focal point to review.

The aim of this narrative review is to summarize the scientific literature available on instruments to assess disease activity during pregnancy in different RDs.

\section{Measurement of disease activity in pregnant patients with rheumatic diseases}

\subsection{Rheumatoid arthritis}

Women have a three-fold higher risk of developing RA than men, and the number of patients experiencing a pregnancy has significantly expanded over the last two decades, polarizing a growing attention on reproductive health matters [6]. An active disease during pregnancy has been clearly demonstrated to increase the risk of preterm delivery and placental insufficiency leading to low birth weight, while the association of pre-eclampsia (PE) and gestational hypertension with active RA is still debated $[7,8]$. Hench, back in 1938, was the first author to describe the ameliorating effects of pregnancy on RA [9]. This observation was confirmed by following early studies, all concordant in reporting high rates of disease improvement or remission during gestation (Table 1). Unfortunately, these findings were to be downsized in forthcoming years: it is now well ascertained that RA improves during pregnancy, but to a much lower extent than what was believed in pioneering times. The explanation of such striking difference should be ascribed to the fact that early reports had a retrospective design, assessed disease activity heterogeneously, often relying on the amelioration of symptoms reported by patients. Furthermore, in modern rheumatology an optimal disease control can be reached, thus limiting the ameliorative potential of pregnancy. However, no modified pregnancy disease activity index has been developed in RA. Studies in the field have investigated a number of different parameters: ESR, $C$ reactive protein (CRP), clinical examination, self-reported activity measures, or clinimetric indices commonly used in clinical practice including visual assessment scale (VAS), disease activity score (DAS28), health assessment questionnaire (HAQ), short-form 36 (SF-36) [10]. As mentioned above, pregnancy itself can potentially affect several of these parameters: ESR physiologically increases during gestation, while fatigue, anemia and arthralgias are quite common in pregnancy, potentially influencing VAS and global health (GH) [11]. Moreover, physical changes related to pregnancy, such as weight gain, can impact functional abilities included in HAQ [11]. Few studies have assessed the performance of the common clinimetric indices during gestation. To note, many studies are from the Dutch Pregnancy-induced Amelioration of Rheumatoid Arthritis (PARA) cohort, which might cause a bias for duplication of data (Table 1). De Man demonstrated that a healthy pregnancy can influence different components of DAS28, with average score increase of 0.22 for $\mathrm{GH}, 1.1$ for ESR, and 0.25 for CRP. Consequently, DAS28-CRP3, excluding the patient GH assessment, emerged as the best tool to assess disease activity in pregnant RA women [11]. More recently, the patient-administered Rheumatoid Arthritis Disease Activity Index (RADAI) has been shown to correlate with DAS28-CRP3 in 32 pregnant RA patients, suggesting that this simple and fast questionnaire could represent a good option to assess disease activity in pregnant RA women, at least outside a rheumatology clinic [12]. Interestingly, in 17 of these 32 patients, Clinical Disease Activity Index (CDAI) was also performed: it correlated well with both DAS28-CRP3 and RADAI, suggesting that CDAI could be useful even during pregnancy [12]. Conversely, Simple Disease Activity Index (SDAI) has never been validated in this setting and is not currently used in RA pregnant women. At present DAS28-CRP3 is addressed as the best clinimetric index to evaluate disease activity in pregnant RA patients, but further studies are needed to define if an ad hoc modified activity score could perform better. 


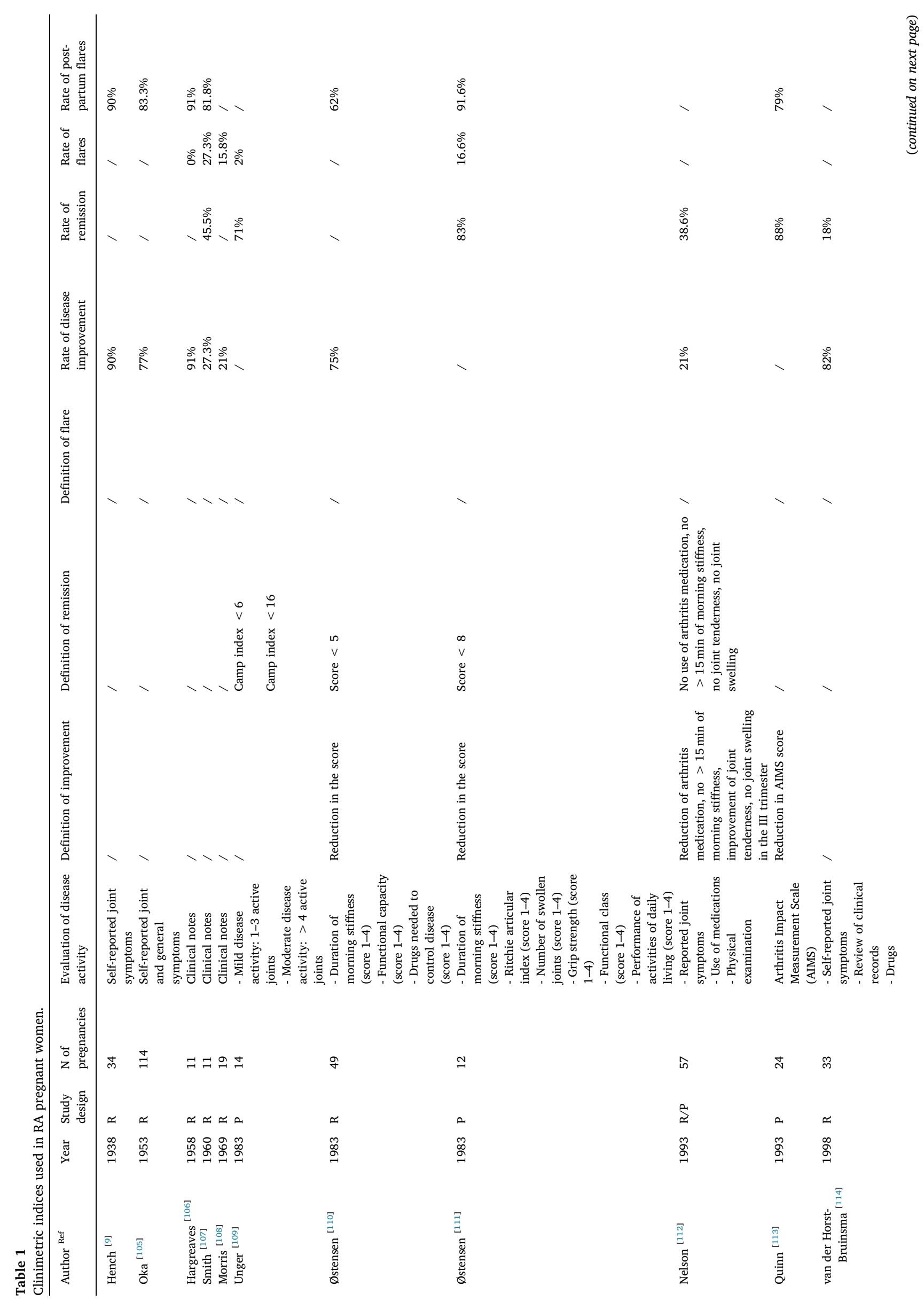




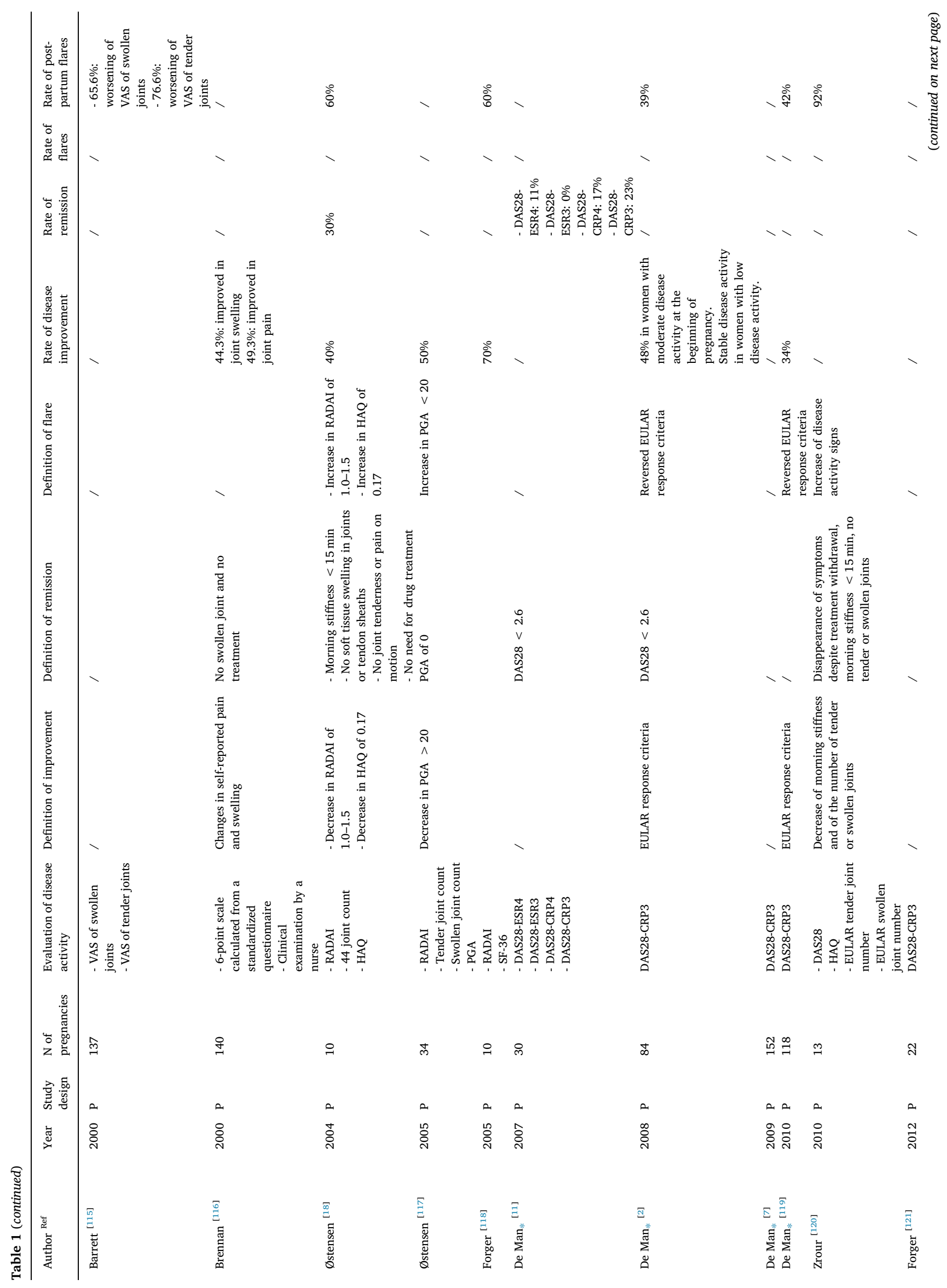




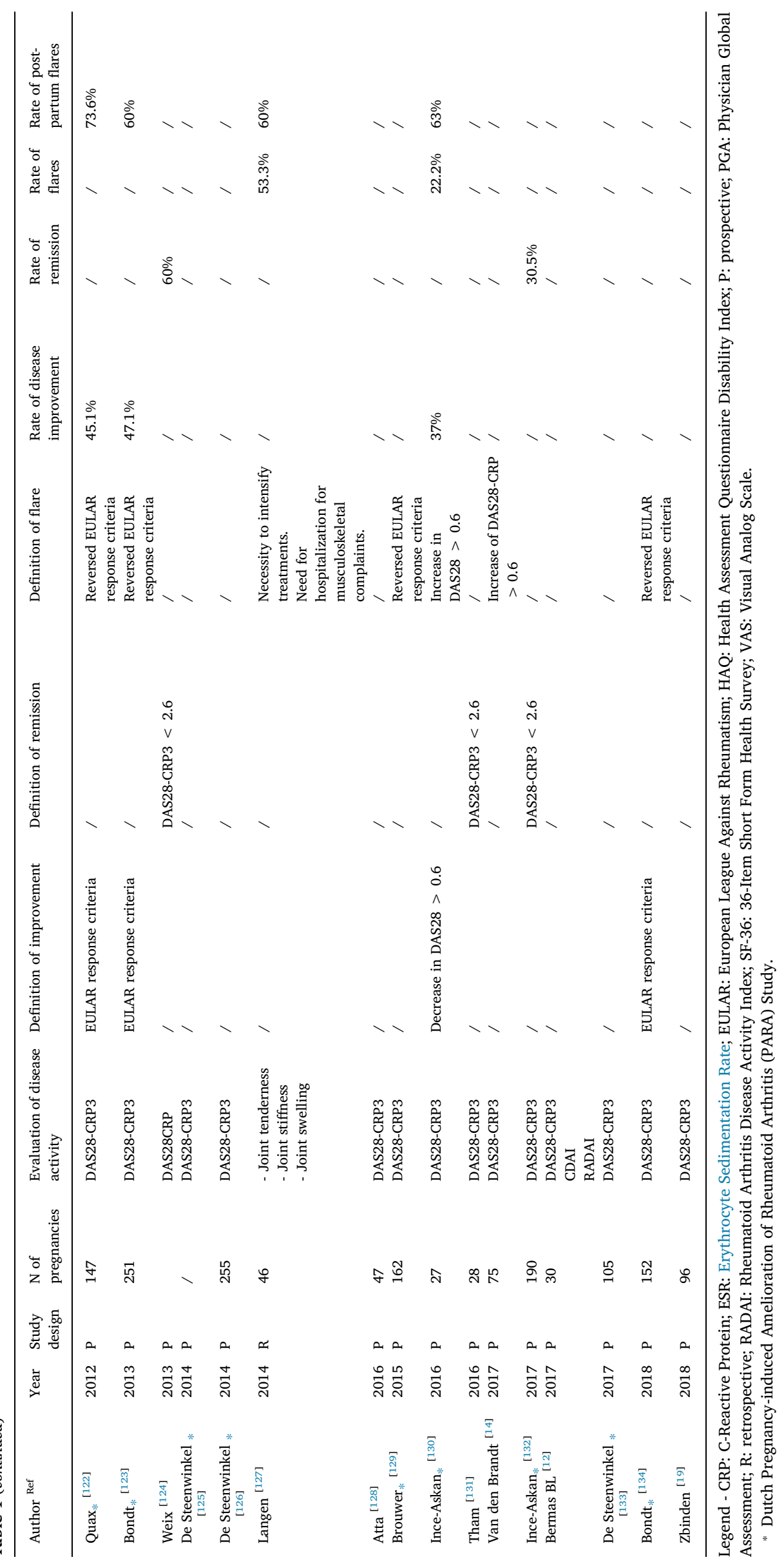




\subsection{Spondyloarthritis}

$\mathrm{SpA}$ are a group of disorders including psoriatic arthritis (PsA) and ankylosing spondylitis (AS) that share similar pathogenic and clinical features [13]. During pregnancy, patients with SpA can experience either an active disease or a stable/reduced disease activity. Recent studies in small cohorts of SpA patients showed a disease flare during pregnancy in $25 \%$ of patients affected by axial SpA [14] while a reduced disease activity was demonstrated in $70 \%$ of AS patients [15]. Several different instruments have been proposed to measure diseases activity in SpA, as unidimensional (focused on joint activity) and as multidimensional (combining different domains) clinimetric indices [16,17]. However, concerning pregnancy and childbearing, no modified indices for disease activity exist for SpA. Standard clinimetric indices were used to measure disease activity during pregnancy in patients affected by AS and PsA. The Bath Ankylosing Spondylitis Activity Index (BASDAI) was used in a prospective study in 9 pregnant women with AS. Higher disease activity scores during the second trimester and a mitigation of symptoms in the third trimester were observed. A good to moderate correlation between most clinical measurements were shown, even if functional indices (including bending), measures of pain and fatigue might be confounded by physiological changes of late pregnancy [18].

Two retrospective studies [14,15] and one prospective study [19] used the Ankylosing Spondylitis Disease Activity Score (ASDAS) during pregnancy in 61 axial SpA patients and 20 AS pregnant women. ASDAS was used to evaluate disease activity, flares and treatment response during pregnancy. Lui and colleagues also evaluated night pain and morning stiffness in 19 AS pregnant women; an improvement in these parameters was registered in the first trimester while a worsening was detected in the third trimester likely secondary to biomechanical loading [20]. Concerning PsA, no robust data are available due to the low sample size. However, women with psoriasis may encounter newonset psoriasis in addition to flares in $45 \%$ of the patients during pregnancy, and in $65 \%$ up to 6 weeks postpartum; the clinimetric index used was the Psoriasis Area and Severity Index (PASI) [21]. In a recent study on 29 PsA women with 42 pregnancies, a worsening of joint and skin activity was found in $31.7 \%$ and $42.9 \%$ respectively, during pregnancy and in the first year after delivery. Joint disease was measured as the number of inflamed joints and based on the definition of the Minimal Disease Activity (MDA) [22]. No modified-pregnancy indices exist for women affected by SpA. Of note, several symptoms such as lumbar night pain, morning stiffness and fatigue could be influenced by pregnancy itself; therefore, disease activity might be overestimated [18]. Moreover, the course of the SpA during pregnancy is extremely variable with some data reporting an improvement and others a worsening of the disease. In the field of SpA, several missing data emerged. Composite clinimetric indices were never tested in SpA pregnant women neither the impact on quality of life, by means of SF-36 or HAQ$\mathrm{SpA}$, were evaluated in this population.

\subsection{Juvenile idiopathic arthritis}

JIA comprises a heterogeneous group of diseases, mainly characterized by the presence of inflammatory arthritis with an onset before 16 years of age [23]. JIA is more frequent in females than in males and in more than one third of patients the disease can persist in adulthood [23]. The dramatic changes in the prognosis resulting from the introduction of biological agents have increased the number of JIA female patients experiencing a pregnancy [24]. However, very few studies have assessed disease activity during gestation in JIA and no validated clinimetric index is currently available. Ursin has recently described the impact of pregnancy on disease activity in 114 women with JIA, using DAS28-CRP3, modified HAQ (MHAQ) and SF-36 [25]. Given the absence of validated clinimetric scores for disease activity of JIA in pregnancy, DAS28-CRP3 could represent a reliable activity index in a disease, very similar to RA.

\subsection{Systemic lupus erythematosus}

In SLE patients, pregnancy is considered at high-risk and it is associated with an increased risk of flares, particularly in patients with active disease at the time of conception [26]. Women with previous lupus nephritis should be carefully managed for the risk of flare during pregnancy and/or the onset of PE [27]. Therefore, a strict assessment and a tight control of disease activity before and throughout pregnancy is crucial; however, physiological changes in pregnancy may mimic a lupus flare (e.g. constitutional symptoms, non-inflammatory joint pain, skin rash, alopecia), as well as, laboratory changes (e.g. anemia, thrombocytopenia, proteinuria, increase of ESR) [26]. There is increasing interest in this topic, as the health conditions of children born to mothers with SLE have been claimed to be possibly associated with maternal disease activity during pregnancy [28] or to the transplacental passage of maternal autoantibodies as in the case of anti-Ro/SSA antibodies [29].

Established lupus activity scales, such as the Lupus Activity Index (LAI), the SLE Disease Activity Index (SLEDAI) and the Systemic Lupus Activity Measure (SLAM), were originally validated in SLE patients excluding pregnant women. In order to reduce confounding features from physiological pregnancy and SLE exacerbations, in 1999 the members of the Systemic Lupus International Cooperating Clinics proposed three modified-pregnancy scores: the SLE-Pregnancy Disease Activity Index (SLEPDAI), the LAI in Pregnancy (LAI-P) and the modified SLAM (m-SLAM) [5]. More recently, two other pregnancy-adapted scores have been introduced, the modified-European consensus lupus activity measurement (m-ECLAM) [30] and the British Isles Lupus Assessment Group-2004 for pregnancy (BILAG2004-P) [31]. The main features of each index are summarized in Table 2.

In the LAI-P, proposed by Khamashta and Ruiz-Irastorza [5], the VAS from the original version was replaced with a graded scale. Some items in the original LAI were excluded (e.g. patient global assessment (PGA) and fatigue) to avoid pregnancy related symptoms to be scored as disease activity and other more objective terms, such as "vasculitis," "fever," or "myositis," were added [32]. The relative weight of every item has also been modified. Manifestations related to APS, such as cerebrovascular accidents or thrombocytopenia, were not scored in LAI$\mathrm{P}$ in patients with antiphospholipid antibodies (aPL) unless other signs of lupus activity were present. The LAI-P includes 4 groups: Group 1 (fever, rash, arthritis and serositis); Group 2 (neurologic, renal, lung, hematologic, vasculitis and myositis); Group 3 (prednisone/NSAIDs/ hydroxychloroquine (HCQ) and immunosuppressants) and Group 4 (proteinuria, anti-DNA, and C3/C4). The LAI-P, validated in 2004 [29], has been recently used to explore the associations between disease activity and medications with offspring birth weight, PE and preterm birth in Swedish pregnant women with SLE [33].

In SLEPDAI, 15 out of the 24 original items of the SELENA-SLEDAI were modified [5]. The 15 items that should be carefully examined before scoring are: seizure, headache, cerebral infarction, cranial nerve disorder, vasculitis, arthritis, hematuria, proteinuria, pyuria, rash, alopecia, pleurisy, low complement levels, thrombocytopenia, and leukopenia. To be considered as a flare of lupus, some pregnancy-related physiological changes must be ruled out, including: 1) PE/ eclampsia (E), and Bell's palsy when considering neurologic involvement; 2) the presence of isolated microscopic hematuria, mild proteinuria ( $<500 \mathrm{mg} / 24 \mathrm{~h}$ ), and/or pyuria (also common in urinary tract or vaginal infections) when considering renal involvement; 3 ) bland joint effusions, frequent during pregnancy; 4) melasma, transient nonspecific facial blush, palmar erythema, and postpartum alopecia when considering cutaneous involvement; 5) mild resting dyspnea before considering pleurisy; 6) PE/E, HELLP (hemolysis elevated liver enzymes low platelet count) syndrome, incidental thrombocytopenia, abruption placentae, fetal demise, and aPL should be considered when there is hematologic involvement such as thrombocytopenia [5]. SLEPDAI has not been formally validated, although it has been used in three studies, 


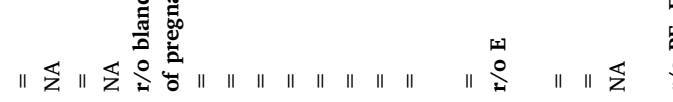

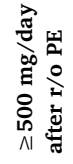

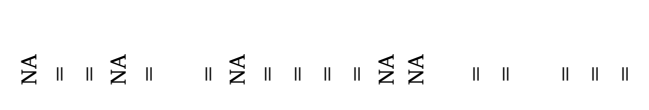

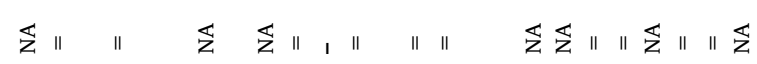

|

离

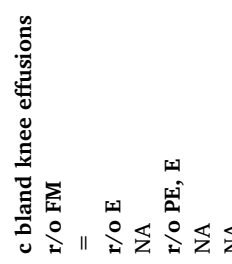

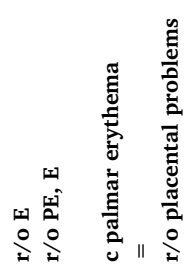

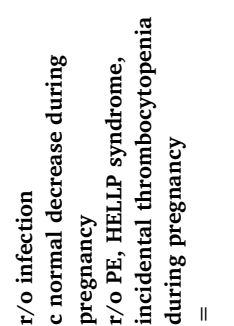

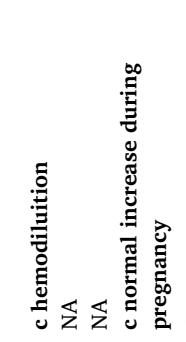

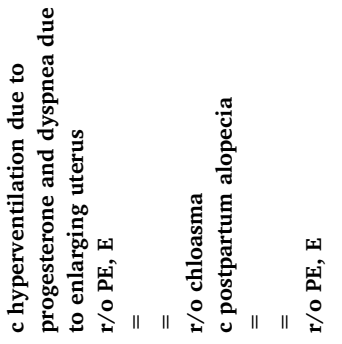

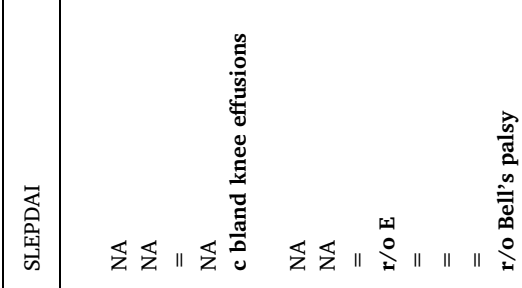

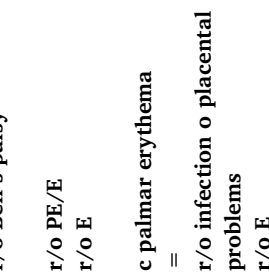

苞
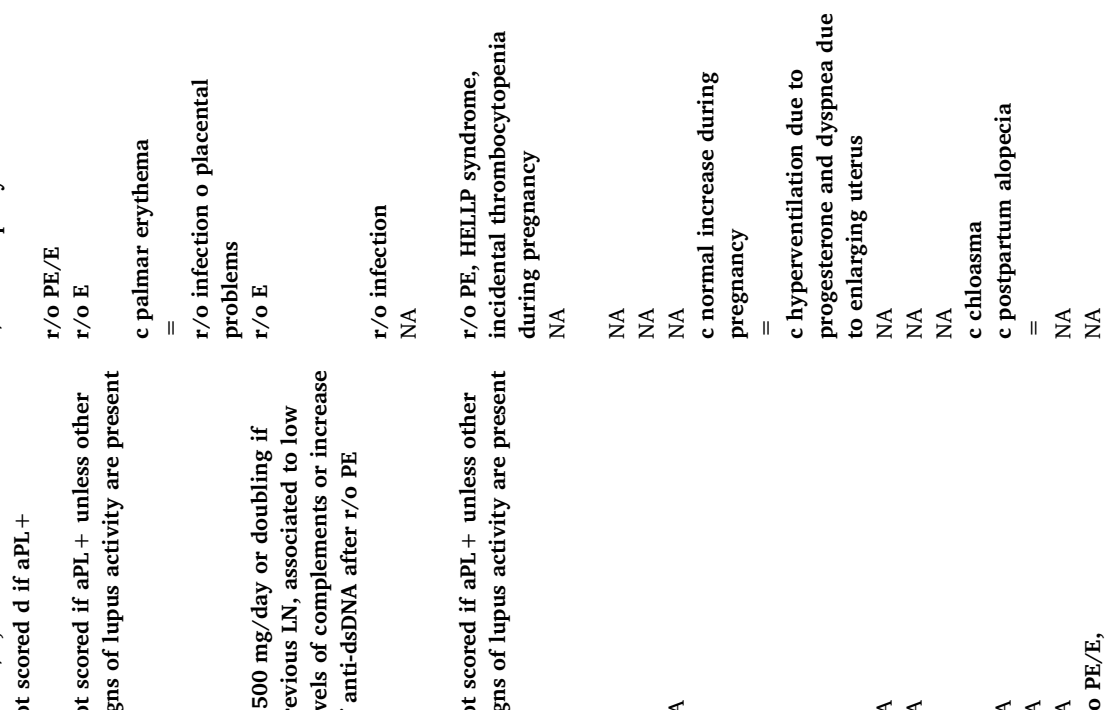

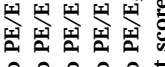

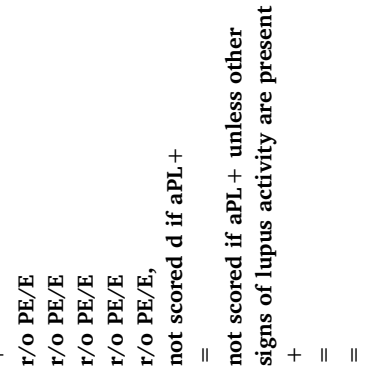

II.

当

\| $\mid$ 艺

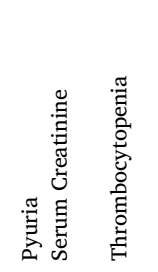

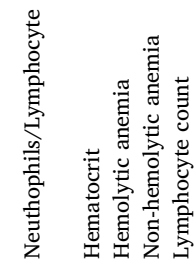

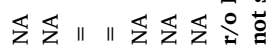

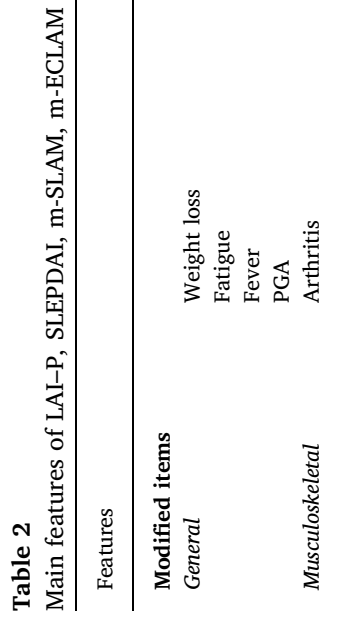

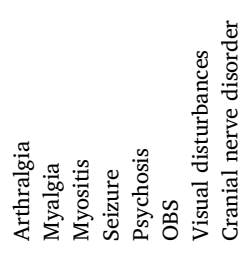

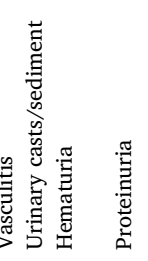
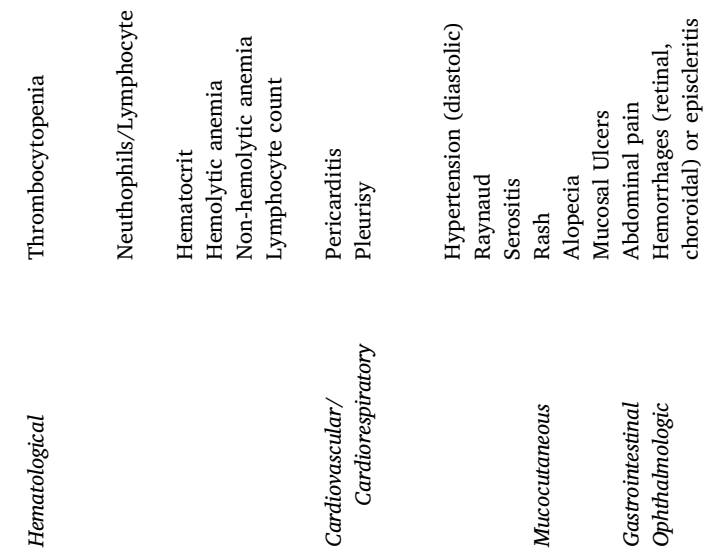


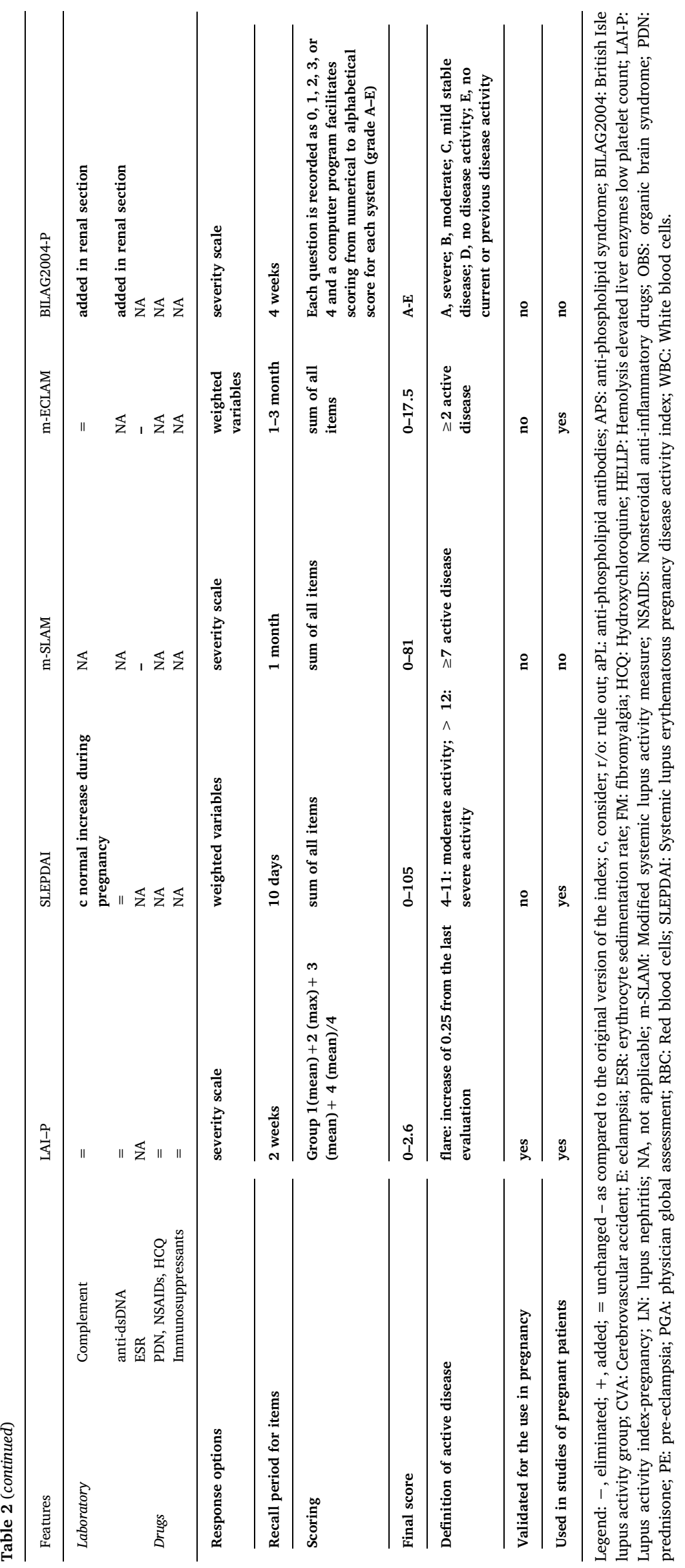


two of which were designed to assess the effect of HCQ on SLE exacerbations in pregnant women $[34,35]$ and one more recent evaluating the complement activation as a predictor of adverse pregnancy outcome in patients with SLE [36].

In 1995, a modification of SLAM-R, the m-SLAM, was proposed by Ramsey-Goldman and colleagues [37]. Some items were eliminated from SLAM-R, such as weight loss, ESR, and the ad hoc scale for miscellaneous disease manifestations [37]. Several descriptors, such as fatigue, myalgia, arthralgia, gastrointestinal symptoms, lymphadenopathy, hepatosplenomegaly, Raynaud's phenomenon, and hypertension, that are not addressed in the SLEPDAI and LAI-P, are included in the mSLAM [5].

In two prospective studies published in 2002 [30] and 2004 [38] Doria et al. used a modified version of ECLAM, the m-ECLAM. Three of the original 15 items were changed as follows: 1) proteinuria considered pathological if $\geq 500 \mathrm{mg} /$ day and after excluding PE; 2) nonhemolytic anemia was not considered due to its high frequency during pregnancy; and 3) ESR was not considered due to its physiological increase during pregnancy [30].

In 2012, the BILAG2004-P index was introduced by Yee and colleagues [31]. The major modification was in the assessment of renal involvement: complement levels (C3 and C4) and anti-dsDNA were added to differentiate proteinuria due to lupus nephritis from PE and hypertension was omitted from the index [31]. Similarly to other indices, the glossary also changed to remind the physician of the confounding items during pregnancy.

In all the above-mentioned indices, modifications were made to address influential items: some were eliminated (e.g. ESR, asthenia) and others were adapted to physiological pregnancy changes (e.g. proteinuria levels), emphasizing the need to differentiate those changes from pregnancy comorbidities (e.g. PE/E). The scoring of each index is calculated in the same way as the original version, except for the LAI-P, in which the weighted score given to each item has been modified. Even though many attempts have been made to develop a pregnancy-specific disease activity index that can be reliable and valid in measuring disease activity, the clinical judgment of an experienced physician remains the gold standard in the management of pregnant women with SLE. As recently recommended [39], these women should be frequently monitored (every 2 to 8 weeks) and during each visit the PGA in conjunction with at least one of the activity tools and pregnancy-specific SLE activity indices (such as SLEPDAI, LAI-P, BILAG 2004-P) should be applied.

\subsection{Anti-phospholipid syndrome}

The assessment of disease activity in APS is different compared to other RDs. As already mentioned, APS can present thrombosis and/or pregnancy complications, as main clinical manifestations. No clinimetric indices exist for APS, but a scoring system has been developed to predict the risk of thrombosis (either first or recurrent) and pregnancy morbidity [40]. Studies in pregnant women with APS, used the occurrence or recurrent of arterial or venous thrombosis, pregnancy complications and non-criteria APS manifestations to assess the disease course during pregnancy [41,42].

\subsection{Other connective tissue diseases}

\subsubsection{Undifferentiated connective tissue disease}

Undifferentiated connective tissue disease (UCTD) is a rheumatic disease with combination of signs and symptoms of connective tissue disease, that does not fulfill criteria for a major CTD. Pregnancies in UCTD have been described and many studies have investigated pregnancy outcome [43]. The evaluation of disease course during pregnancy has also been assessed. Mosca et al. studied a population of 20 UCTD patients during their 25 pregnancies to investigate disease flare during pregnancy, pregnancy course and to determinate if pregnancy could be a trigger for disease evolution to a defined CTD. Flare in UCTD was defined as a disease activity increase based on physician's assessment and on therapeutic changes [44]. Also, Castellino et al. studied the outcome of 55 pregnancies in 50 UCTD patients followed during pregnancy and 6 months after delivery; maternal outcome was also investigated to detect disease relapse or differentiation into defined CTD comparing the ouctome of pregnant patients with a control-population of 53 non-pregnant UCTD followed for 16 months. Disease flare was based on clinical judgment: new onset or worsening of preexisting symptoms and/or treatment modifications [45]. So, at present, no validated indices have been proposed to assess disease activity in UCTD patients and clinical judgment still is the gold standard for both pregnant and non-pregnant patients.

\subsubsection{Mixed connective tissue diseases}

Mixed connective tissue disease (MCTD) is an autoimmune CTD characterized by an overlap syndrome with features of lupus, scleroderma, and poly/dermatomyositis (PM/DM), in patients who carry positivity for anti-U1 ribonucleoprotein (RNP) autoantibodies. Patients may exhibit manifestations of any of the composing diseases during the course of the disease [46].

MCTD primarily affects women during the years of childbearing potential [47]; their fertility rates seem to be similar to adjusted agematched controls. A small number of MCTD cases showed its onset during pregnancy, and definite MCTD have been reported having flares during gestation: a worsening or new onset of clinical manifestations (e.g. worsening of interstitial lung disease, arthritis) were used to describe a disease flare [48-52]. A study focusing on MCTD pregnancy outcome [53] reported a case of a pregnant patient affected by pulmonary arterial hypertension (PAH). The patient was clinically stable, as monitored by six minutes walking test before and during the pregnancy. To date, no validated indices exist to assess disease activity in pregnant and non-pregnant women with MCTD.

\subsubsection{Inflammatory myopathies}

$\mathrm{DM}$ and PM are autoimmune inflammatory myopathies (IM) characterized by proximal symmetric muscle weakness and, in case of DM, a large variety of skin manifestations [54]. As other autoimmune diseases, they predominantly affect female gender [55]. Since the two peaks of IM onset are in childhood and over the age of 45 years, women in reproductive age group are uncommonly affected [54]. Indeed, the proportion of IM onset from 25 to 34 years is estimated to be $4-11 \%$ [56]. As a consequence, pregnancies in patients affected with IM are rare.

To date, two international collaborative groups, the International Myositis Assessment and Clinical Studies Group (IMACS) and the Paediatric Rheumatology International Trials Organisation (PRINTO), have defined consensus core set measures to assess myositis disease activity and damage in adults and children and have begun to validate and standardize these measures [57,58].

No recommendations on how to assess IM activity and damage during pregnancy have been done, given the small sample size of the few relevant studies. Thus, the optimal assessment of pregnancy outcome and disease activity in IM patients during pregnancy remains elusive.

IM activity has been defined in some studies by the presence of any rash, muscle weakness and elevation of muscle serum enzymes [59]. Cutaneous manifestations included Gottron papules and heliotrope rash, whereas serum muscle enzymes consist in elevation of creatinekinase (CK) and/or lactate dehydrogenase (LDH) [60].

A recent study [60] assessed disease activity in pregnant patients by performing both the UK Medical research council system scale (0-5) and the manual muscle strength testing (MMT).

Therefore, the clinimetric indices for IM should be further investigated during pregnancy. 


\subsubsection{Sjögren's syndrome}

Sjögren's syndrome (SS) is an autoimmune systemic disease characterized by dysfunction of exocrine glands and possible multiorgan involvement. Disease activity indices have been created to evaluate two different aspects of the disease: patient's symptoms and systemic activity. Different indices were proposed in the past to assess disease activity but currently no indices have been modified and validated for pregnant SS patients. Many studies have investigated the interaction between SS and pregnancy, but they all focused on pregnancy outcome $[61,62]$. Only one study by Priori et al. investigated maternal disease during pregnancy and one year post-partum. In this study, no disease activity index was used to assess disease, but flares were defined as the onset or worsening of symptoms leading to therapeutic changes [63].

\subsubsection{Systemic sclerosis}

Systemic sclerosis (SSc) is a really unpredictable disease. Even if studies published during the last years demonstrated that the majority of women with SSc do not undergo significant modifications of disease activity during pregnancy, neither have worsening of symptoms after delivery [49,64-66], there is a risk of worsening of the disease for some SSc women who have organ involvement such as lungs, heart, and kidneys [66]. Thus, a close monitoring of internal organs and skin involvement, blood pressure and monthly blood tests is mandatory. Until today, there are no validated indices to analyze disease activity, severity and outcome during pregnancy, so that all the studies conducted till now just considered disease progression as changes in organ involvement $[64,65,67,68]$. Indeed, the definition of disease activity in SSc pregnancy cannot be done using a single variable and the disease activity indices proposed in the literature (the European Scleroderma
Study Group (EScSG) activity index, the 12-point DAI, EUSTAR activity index, and the Combined Response Index for Systemic Sclerosis (CRISS)) are preliminary or provisional, not fully validated and not used in studies on pregnancy [69-71]. In the IMPRESS 1 study, a Medsger severity score $>2$ in at least 1 item and changes in organ involvements and laboratory exams were used to assess the maternal outcomes in pregnant SSc women [65].

\subsection{Systemic vasculitis}

Most of the literature focuses on pregnancies in women with Behçet disease (BD) and Takayasu arteritis (TA) because of the earlier median age of onset, however, cases of pregnancy during antineutrophil cytoplasmic antibody (ANCA)-associated vasculitis (AAV) have also been reported in the literature.

AAV are small-vessel, necrotizing vasculitis primarily affecting the respiratory tract, lungs, kidney, and peripheral nervous system [72]. At present, there is no specific clinical instrument to assess AAV disease activity during pregnancy. In the majority of the studies performed in AAV pregnant patients, disease activity was scored using the Birmingham Vasculitis Activity Score (BVAS) [73] whilst damage due to vasculitis was scored by the Vasculitis Damage Index (VDI) [74]; furthermore, most studies collected the characteristics of the patients (age, type of AAV, organ involvement, ANCA status, ongoing and previous treatment), maternal outcomes (renal function, arterial hypertension, PE), fetal and neonatal outcomes (fetal growth restriction (FGR), prematurity, birth weight, perinatal mortality), type of delivery [75-83]. In the majority of reported cases, women with AAV in remission had a favorable maternal and neonatal outcome with quiescent disease or

Table 3

Disease activity indices used in clinical studies involving pregnant women with Rheumatic diseases.

\begin{tabular}{|c|c|c|c|}
\hline Rheumatic diseases & $\begin{array}{l}\text { Modified pregnancy } \\
\text { indices }\end{array}$ & Standard indices used in studies during pregnancy & Other outcome measures used in studies during pregnancy \\
\hline RA & - & DAS28-CRP3; RADAI; DAS28-ESR or CRP4; CDAI & $\begin{array}{l}\text { Self-reported joints; morning stiffness; Reported joint symptoms and/or } \\
\text { treatment modification }\end{array}$ \\
\hline AS & - & BASDAI; ASDAS & - \\
\hline PsA & - & ASDAS; PASI; MDA & $\begin{array}{l}\text { Worsening of joint activity and worsening of skin activity (Physician's } \\
\text { Judgment) }\end{array}$ \\
\hline JIA & - & DAS28-CRP3 & - \\
\hline SLE & $\begin{array}{l}\text { LAI-P; SLEPDAI; m- } \\
\text { SLAM; } \\
\text { m-ECLAM; BILAG2004- } \\
\text { P }\end{array}$ & SLEDAI; PGA & $\begin{array}{l}\text { Clinical and laboratory assessment and/or treatment modification } \\
\text { (Physicians Judgment) }\end{array}$ \\
\hline APS & - & - & - \\
\hline UCTD & - & - & $\begin{array}{l}\text { Worsening or new onset of clinical manifestations and/or treatment } \\
\text { modification (Physician's Judgment) }\end{array}$ \\
\hline MTCD & - & - & $\begin{array}{l}\text { Worsening or new onset of clinical manifestations and/or treatment } \\
\text { modification (Physician's Judgment) }\end{array}$ \\
\hline $\mathrm{DM}$ & - & UK medical research council system scale; MMT & $\begin{array}{l}\text { Cutaneous manifestations (Gottron's papules, heliotrope rash) (Physician's } \\
\text { Judgment) and elevated muscle enzymes levels (CK, LDH) }\end{array}$ \\
\hline PM & - & UK medical research council system scale; MMT & - \\
\hline SS & - & - & $\begin{array}{l}\text { Worsening or new onset of clinical manifestations and/or treatment } \\
\text { modification (Physician's Judgment) }\end{array}$ \\
\hline SSc & - & $\begin{array}{l}\text { Medsger severity score }>2 \text { (in at least } 1 \text { item and } \\
\text { changes in organ involvement) }\end{array}$ & - \\
\hline AAV & - & BVAS; VDI & Typical complications: respiratory, cutaneous, articular, renal \\
\hline TakA & - & Kerr/NIH index & Two new-onset or worsening items in the previous 3 months \\
\hline $\mathrm{BD}$ & - & - & $\begin{array}{l}\text { Onset of new clinical manifestations or increased frequency of symptoms } \\
\text { requiring treatment changes (Physician's Judgment) }\end{array}$ \\
\hline
\end{tabular}

Legend- A/V: arterial/venous; AAV: ANCA-associated vasculitis; ANCA: antineutrophil cytoplasmic antibody; APS: antiphospholipid syndrome; AS: ankylosing spondylitis; ASDAS: Ankylosing Spondylitis Disease Activity Score; BASDAI: Bath Ankylosing Spondylitis Activity Index; BD: Behçet disease; BILAG2004-P: British Isles Lupus Assessment Group-2004 for pregnancy; BVAS: Birmingham Vasculitis Activity Score; CDAI: clinical disease activity index; CK: creatine kinase; DAS28CRP3: disease activity score 28 joints count-C reactive protein; DAS28-ESR: disease activity score 28 joints count-erythrocyte sedimentation rate; JIA: juvenile idiopathic arthritis; LAI-P: Lupus Activity Index in Pregnancy; LDH: lactate dehydrogenase; m-ECLAM: modified-European consensus lupus activity measurement; mSLAM: modified Systemic Lupus Activity Measure; MDA: Minimal Disease Activity; NIH: National Institutes of Health; PASI: Psoriasis Area and Severity index; PGA: Patients Global Assessment; PsA: psoriatic arthritis; RA: rheumatic arthritis; RADAI: rheumatoid arthritis disease activity index; SLE: systemic lupus erythematosus; SLEDAI: SLE Disease Activity Index; SLEPDAI: SLE-Pregnancy Disease Activity Index; SS: Sjögren syndrome; SSc: systemic sclerosis; TakA: Takayasu arteritis; UCTD: undifferentiated connective tissue disease; UK: United Kingdom; MMT: manual muscle strength testing; VDI: Vasculitis Damage Index. 
only minor glucocorticoids-dose adjustment; conversely, outcomes were poorer when pregnancies were conceived during active disease or when AAV started during pregnancy [3,75-86]. The most frequent complications were respiratory, cutaneous, articular and renal flares, arterial hypertension, PE, prematurity [3,75-86]. By using BVAS during pregnancy, great attention should be paid to the evaluation of renal, central nervous system and constitutional symptoms that can be confounded by physiological (e.g. proteinuria) or pathological changes (e.g. PE). The item "ischemic abdominal pain" deserves a special mention because it can mimic the abdominal pain during PE.

TA is a large vessel vasculitis primarily affecting aorta and its major branches [87]. At present, a validated clinical instrument to assess TA disease activity in pregnancy does not exist. Some studies in pregnant TA patients used the Kerr/NIH index $[88,89]$ that assesses four items: constitutional manifestations, raised ESR, manifestations of vascular ischemia, angiographic features indicative of vasculitis: disease is defined as active in case of at least two new or worsened items in the previous three months. Nevertheless, items such as ESR and musculoskeletal symptoms can be influenced by pregnancy, so they should be interpreted with caution. Furthermore, most of the studies $[3,84,88-93]$ took into account the general characteristics of the subjects (age, type of arterial involvement, parity, previous obstetric complications), maternal outcomes (glucocorticoid dose increase, CRP and ESR, arterial hypertension, PE, renal and cardiac failure, cardiovascular events), fetal and neonatal outcomes (FGR, prematurity, birth weight, perinatal mortality, Apgar score at $5 \mathrm{~min}$ ) [3,84,88-95].

Pregnancy does not seem to affect disease activity in TA patients [80], nevertheless, maternal complications such as sustained hypertension, $\mathrm{PE}$, congestive heart failure and cerebrovascular accidents are not uncommon [3,84,88-96].

BD is a multisystemic disorder of unknown etiology characterized by mucocutaneous, ocular, vascular, and central nervous system manifestations [97]. No validated indices assessing BD disease activity in pregnancy are currently available. Disease flares were usually defined as the onset of new symptoms or increased frequency of symptoms requiring treatment changes during pregnancy. Studies on BD pregnancies also evaluated patient's characteristics (age, organ involvement, ongoing and previous treatment), maternal outcomes (arterial hypertension, PE, glucocorticoid dose increase), and fetal/neonatal outcomes (prematurity, low birth weight, perinatal mortality, neonatal intensive care unit admission) [3,84,97]. Pregnancy does not seem to affect disease activity; only around one third of reported cases experiences relapse, primarily with mucocutaneous and ocular manifestations [85,98-100]. In the majority of reported cases, women with BD had pregnancy outcomes similar to those seen in general population even though complications as preterm birth, pregnancy loss, and thrombotic events during pregnancy and puerperium have also been reported [101-104].

\section{Conclusions}

The physiologic and pathological changes that occur during pregnancy need to be reflected in existing instruments for non-pregnant patient with RDs (Table 3).

To date, SLE is the only disease with modified-pregnancy indices. Five commonly utilized instruments have been modified to account for several adaptations which might confound the attribution of signs or symptoms to disease activity: SLEPDAI, LAI-P, m-SLAM, m-ECLAM and BILAG2004-P.

No modified-pregnancy indices exist for women affected by other RDs. In RA, JIA, SpA and Systemic Vasculitis standard validated indices have been used to assess disease activity in pregnant woman. The DAS28-CRP3 resulted as the best instrument to evaluate disease activity in pregnant RA patients. In other RDs without a validated clinimetric index to assess disease activity, such as SS, MCTD, UCTD, and SSc, studies in pregnant women are scarce and the evaluation of disease activity is still based on the physician's judgment.

Therefore, there is a need to develop modified-pregnancy clinimetric indices to ensure continuity of assessments when RDs patients become pregnant in long-term longitudinal studies. Furthermore, consistent use of a standardized and validated disease activity outcome measure in the assessment of pregnant RDs patients may help address the scarce and, sometimes, conflicting reports of the effects of pregnancy on exacerbation of RDs.

The elaboration and standardization of measure to assess disease activity in pregnant women with RDs will enable us to improve the accuracy of advice to women during pregnancy and to develop better management protocols.

\section{Conflict of interest}

All authors have no conflict of interest.

\section{References}

[1] Østensen M, Cetin I. Autoimmune connective tissue diseases. Best Pract Res Clin Obstet Gynaecol 2015;29(5):658-70.

[2] de Man YA, Dolhain RJEM, van de Geijn FE, Willemsen SP, Hazes JMW. Disease activity of rheumatoid arthritis during pregnancy: results from a nationwide prospective study. Arthritis Rheum 2008;59(9):1241-8.

[3] Fredi M, Lazzaroni MG, Tani C, Ramoni V, Gerosa M, Inverardi F, et al. Systemic vasculitis and pregnancy: a multicenter study on maternal and neonatal outcome of 65 prospectively followed pregnancies. Autoimmun Rev 2015;14(8):686-91.

[4] Østensen M. Preconception counseling. Rheum Dis Clin North Am 2017;43(2):189-99.

[5] Buyon JP, Kalunian KC, Ramsey-Goldman R, Petri MA, Lockshin MD, RuizIrastorza G, et al. Assessing disease activity in SLE patients during pregnancy. Lupus 1999;8(8):677-84

[6] Østensen M, Andreoli L, Brucato A, Cetin I, Chambers C, Clowse ME, et al. State of the art: reproduction and pregnancy in rheumatic diseases. Autoimmun Rev 2015; 14(5):376-86.

[7] de Man YA, Hazes JM, van der Heide H, Willemsen SP, de Groot CJ, Steegers EA, et al. Association of higher rheumatoid arthritis disease activity during pregnancy with lower birth weight: results of a national prospective study. Arthritis Rheum 2009;60(11):3196-206.

[8] Bharti B, Lee SJ, Lindsay SP, Wingard DL, Jones KL, Lemus H, et al. Disease severity and pregnancy outcomes in women with rheumatoid arthritis: results from the organization of teratology information specialists autoimmune diseases in pregnancy project. J Rheumatol 2015;42(8):1376-82.

[9] Hench P. The ameliorating effect of pregnancy on chronic atrophic (infectious rheumatoid) arthritis, fibrositis and intermittent hydrarthritis. Mayo Clin Proc 1938;13:161-7.

[10] Hazes JMW, Coulie PG, Geenen V, Vermeire S, Carbonnel F, Louis E, et al. Rheumatoid arthritis and pregnancy: evolution of disease activity and pathophysiological considerations for drug use. Rheumatology 2011;50(11):1955-68.

[11] Y A de Man, Hazes JMW, van de Geijn FE, Krommenhoek C, Dolhain RJEM. Measuring disease activity and functionality during pregnancy in patients with rheumatoid arthritis. Arthritis Rheum 2007;57(5):716-22.

[12] Bermas BL, Tedeschi SK, Frits M, Shadick NA. An evaluation of the patient-administered Rheumatoid Arthritis disease activity Index for assessing disease activity during pregnancy. Rheumatology (Oxford) 2017;56(12):2237-9.

[13] Dougados M, Baeten D. Spondyloarthritis. Lancet 2011;377:2127-37.

[14] van den Brandt S, Zbinden A, Baeten D, Villiger PM, Østensen M, Förger F. Risk factors for flare and treatment of disease flares during pregnancy in rheumatoid arthritis and axial spondyloarthritis patients. Arthritis Res Ther 2017;19(1):64.

[15] Timur H, Tokmak A, Türkmen GG, Ali Inal H, Uygur D, Danişman N. Pregnancy outcome in patients with ankylosing spondylitis. J Matern Neonatal Med 2016;29(15):2470-4.

[16] Van Der Heijde D, Lie E, Kvien TK, Sieper J, Van den Bosch F, Listing J, et al ASDAS, a highly discriminatory ASAS-endorsed disease activity score in patients with ankylosing spondylitis. Ann Rheum Dis 2009;68(12):1811-8.

[17] Coates LC, Fransen J, Helliwell PS. Defining minimal disease activity in psoriatic arthritis: a proposed objective target for treatment. Ann Rheum Dis 2010;69(1):48-53.

[18] Østensen M, Fuhrer L, Mathieu R, Seitz M, Villiger PM. A prospective study of pregnant patients with rheumatoid arthritis and ankylosing spondylitis using validated clinical instruments. Ann Rheum Dis 2004;63:1212-7.

[19] Zbinden A, van den Brandt S, Østensen M, Villiger PM, Förger F. Risk foradverse pregnancy outcome in axial spondyloarthritis and rheumatoid arthritis: disease activity matters. Rheumatology (Oxford) 2018 Mar 30. https://doi.org/10.1093/ rheumatology/key053.

[20] Lui NL, Haroon N, Carty A, Shen H, Cook RJ, Shanmugarajah S, et al. Effect of pregnancy on ankylosing spondylitis: A case-control study. J Rheumatol 2011;38(11):2442-4

[21] Bobotsis R, Gulliver WP, Monaghan K, Lynde C, Fleming P. Psoriasis and adverse pregnancy outcomes: a systematic review of observational studies. Br J Dermatol 2016;175(3):464-72

[22] Polachek A, Li S, Polachek IS, Chandran V, Gladman D. Psoriatic arthritis disease activity during pregnancy and the first-year postpartum. Semin Arthritis Rheum 
2017;46(6):740-5.

[23] Prakken B, Albani S, Martini A. Juvenile idiopathic arthritis. Lancet 2011;377(9783):2138-49.

[24] Remaeus K, Johansson K, Askling J, Stephansson O. Juvenile onset arthritis and pregnancy outcome: a population-based cohort study. Ann Rheum Dis 2017;76(11):1809-14.

[25] Ursin K, Lydersen S, Skomsvoll JF, Wallenius M. Disease activity of juvenile idiopathic arthritis during and after pregnancy: a prospective multicenter study. J Rheumatol 2018;45(2):257-65.

[26] Singh AG, Chowdhary VR. Pregnancy-related issues in women with systemic lupus erythematosus. Int J Rheum Dis 2015;18(2):172-81.

[27] Schreiber K, Stach K, Sciascia S. Lupus nephritis and pregnancy outcome. Autoimmun Rev 2017;16(4):433-4.

[28] Yousef Yengej FA, van Royen-Kerkhof A, Derksen RHWM, Fritsch-Stork RDE. The development of offspring from mothers with systemic lupus erythematosus. A systematic review. Autoimmun Rev 2017;16(7):701-11.

[29] Zuppa AA, Riccardi R, Frezza S, Gallini F, Luciano RM, Alighieri G, et al. Neonatal lupus: follow-up in infants with anti-SSA/Ro antibodies and review of the literature. Autoimmun Rev 2017;16(4):427-32.

[30] Doria A, Cutolo M, Ghirardello A, Zampieri S, Vescovi F, Sulli A, et al. Steroid hormones and disease activity during pregnancy in systemic lupus erythematosus. Arthritis Rheum 2002;47(2):202-9.

[31] Yee CS, Akil M, Khamashta M, Bessant R, Kilding R, Giles I, et al. The BILAG2004pregnancy index is reliable for assessment of disease activity in pregnant SLE patients. Rheumatol (United Kingdom) 2012;51(10):1877-80.

[32] Ruiz-Irastorza G, Khamashta MA, Gordon C, Lockshin MD, Johns KR, Sammaritano L, et al. Measuring systemic lupus erythematosus activity during pregnancy: Validation of the lupus activity index in pregnancy scale. Arthritis Care Res (Hoboken). 2004;51(1):78-82.

[33] Skorpen CG, Lydersen S, Gilboe I-M, Skomsvoll JF, Salvesen KÅ, Palm Ø, et al. Influence of disease activity and medications on offspring birth weight, preeclampsia and preterm birth in systemic lupus erythematosus: a population-based study. Ann Rheum Dis 2018;77(2):264-9.

[34] Levy RA, Vilela VS, Cataldo MJ, Ramos RC, Duarte JL, Tura BR, et al. Hydroxychloroquine (HCQ) in lupus pregnancy: Double-blind and placebo-controlled study. Lupus 2001;10(6):401-4.

[35] Kroese SJ, De Hair MJH, Limper M, Lely AT, van Laar JM, Derksen RHWM, et al. Hydroxychloroquine use in lupus patients during pregnancy is associated with longer pregnancy duration in preterm births. J Immunol Res 2017;2017:2810202.

[36] Kim MY, Guerra MM, Kaplowitz E, Laskin CA, Petri M, Branch DW, et al. Complement activation predicts adverse pregnancy outcome in patients with systemic lupus erythematosus and/or antiphospholipid antibodies. Ann Rheum Dis 2018;77(4):549-55.

[37] Ramsey-Goldman R, Manzi SSE, et al. Lupus activity in pregnant and non-pregnant women (abstract). Arthritis Rheum 1995:S219.

[38] Doria A, Ghirardello A, Iaccarino L, Zampieri S, Punzi L, Tarricone E, et al. Pregnancy, cytokines, and disease activity in systemic lupus erythematosus. Arthritis Rheum 2004;51(6):989-95.

[39] Andreoli L, Bertsias GK, Agmon-Levin N, Brown S, Cervera R, CostedoatChalumeau N, et al. EULAR recommendations for women's health and the management of family planning, assisted reproduction, pregnancy and menopause in patients with systemic lupus erythematosus and/or antiphospholipid syndrome. Ann Rheum Dis 2017;76(3):476-85.

[40] Sciascia S, Bertolaccini ML, Roccatello D, Khamashta MA. Independent validation of the antiphospholipid score for the diagnosis of antiphospholipid syndrome. Ann Rheum Dis 2013;72(1):142-3.

[41] Chighizola CB, Andreoli L, Gerosa M, Tincani A, Ruffatti A, Meroni PL. The treatment of anti-phospholipid syndrome: A comprehensive clinical approach. J Autoimmun 2018;90:1-27.

[42] Mekinian A, Alijotas-Reig J, Carrat F, Costedoat-Chalumeau N, Ruffatti A, Lazzaroni MG, et al. Refractory obstetrical antiphospholipid syndrome: Features, treatment and outcome in a European multicenter retrospective study. Autoimmun Rev 2017;16(7):730-4.

[43] Spinillo A, Beneventi F, Caporali R, Ramoni V, Montecucco C. Undifferentiated connective tissue diseases and adverse pregnancy outcomes. An undervalued association? Am J Reprod Immunol 2017;78(6).

[44] Mosca M, Neri R, Strigini F, Carmignani A, Totti D, Tavoni A, et al. Pregnancy outcome in patients with undifferentiated connective tissue disease: a preliminary study on 25 pregnancies. lupus 2002;11(5):304-7.

[45] Castellino G, Capucci R, Bernardi S, Padovan M, Giacuzzo S, Pivato E, et al. Pregnancy in patients with undifferentiated connective tissue disease: a prospective case-control study. Lupus 2011;20(12):1305-11.

[46] Sharp GC, Irvin WS, Tan EM, Gould RG, Holman HR. Mixed connective tissue disease-an apparently distinct rheumatic disease syndrome associated with a specific antibody to an extractable nuclear antigen (ENA). Am J Med 1972;52(2):148-59.

[47] Aringer M, Steiner G, Smolen JS. Does mixed connective tissue disease exist? Yes. Rheum Dis Clin North Am 2005;31(3):411-20.

[48] Chitayat D, Keating S, Zand DJ, Costa T, Zackai EH, Silverman E, et al. Chondrodysplasia punctata associated with maternal autoimmune diseases: expanding the spectrum from systemic lupus erythematosus (SLE) to mixed connective tissue disease (MCTD) and scleroderma report of eight cases. Am J Med Genet Part A 2008;146(23):3038-53.

[49] Chung L, Flyckt RLR, Colon I, Shah AA, Druzin M, Chakravarty EF. Outcome of pregnancies complicated by systemic sclerosis and mixed connective tissue disease. Lupus 2006;15(9):595-9.

[50] Lundberg I, Hedfors E. Pregnancy outcome in patients with high titer anti-RNP antibodies. A retrospective study of 40 pregnancies. J Rheumatol 1991;18(3):359-62.

[51] Boggess KA, Easterling TR, Raghu G. Management and outcome of pregnant women with interstitial and restrictive lung disease. Am J Obstet Gynecol 1995;173(4):1007-14

[52] Nelson-Piercy C, Agarwal S, Lams B. Lesson of the month: selective use of cyclophosphamide in pregnancy for severe autoimmune respiratory disease. Thorax 2016;71(7):667-8.

[53] Goya M, Meseguer ML, Merced C, Suy A, Monforte V, Domingo E, et al. Successful pregnancy in a patient with pulmonary hypertension associated with mixed collagen vascular disease. J Obstet Gynaecol (Lahore) 2014;34(2):191-2.

[54] Doria A, Iaccarino L, Ghirardello A, Briani C, Zampieri S, Tarricone E, et al. Pregnancy in rare autoimmune rheumatic diseases: UCTD, MCTD, myositis, systemic vasculitis and Beçhet disease. Lupus 2004;13:690-5.

[55] Ohta A, Nagai M, Nishina M, Tomimitsu H, Kohsaka H. Age at onset and gender distribution of systemic lupus erythematosus, polymyositis/dermatomyositis, and systemic sclerosis in Japan. Mod Rheumatol 2013;23(4):759-64.

[56] Zhong Z, Lin F, Yang J, Zhang F, Zeng X, You X. Pregnancy in polymyositis or dermatomyositis: retrospective results from a tertiary Centre in China. Rheumatology (Oxford) 2017;56(8):1272-5.

[57] Miller FW, Rider LG, Chung YL, Cooper R, Danko K, Farewell V, et al. Proposed preliminary core set measures for disease outcome assessment in adult and juvenile idiopathic inflammatory myopathies. Rheumatology (Oxford) 2001;40(11):1262-73.

[58] Ruperto N, Ravelli A, Pistorio A, Ferriani V, Calvo I, Ganser G, et al. The provisional Paediatric Rheumatology International Trials Organisation/American College of Rheumatology/European League against Rheumatism disease activity core set for the evaluation of response to therapy in juvenile dermatomyositis: a prospective validation study. Arthritis Rheum 2008;59(1):4-13.

[59] Nagy-Vincze M, Vencovsky J, Lundberg IE, Dankó K. Pregnancy outcome in idiopathic inflammatory myopathy patients in a multicenter study. J Rheumatol 2014;41(12):2492-4.

[60] Váncsa A, Ponyi A, Constantin T, Zeher M, Dankó K. Pregnancy outcome in idiopathic inflammatory myopathy. Rheumatol Int 2007;27(5):435-9.

[61] Upala S, Yong WC, Sanguankeo A. Association between primary Sjögren's syndrome and pregnancy complications: a systematic review and meta-analysis. Clin Rheumatol 2016;35(8):1949-55.

[62] Gupta S, Gupta N. Sjögren syndrome and pregnancy: a literature review. Perm J 2017; 21. pii: 16-047.

[63] Priori R, Gattamelata A, Modesti M, Colafrancesco S, Frisenda S, Minniti A, et al. Outcome of pregnancy in Italian patients with primary Sjögren syndrome. J Rheumatol 2013;40(7):1143-7.

[64] Steen VD, Medsger TA. Fertility and pregnancy outcome in women with systemic sclerosis. Arthritis Rheum 1999;42(4):763-8.

[65] Taraborelli M, Ramoni V, Brucato A, Airò P, Bajocchi G, Bellisai F, et al. Brief report: successful pregnancies but a higher risk of preterm births in patients with systemic sclerosis: an Italian multicenter study. Arthritis Rheum 2012;64(6). (1970-197).

[66] Betelli M, Breda S, Ramoni V, Paris F, Rampello S, Limonta M, et al. Pregnancy in systemic sclerosis. J Scleroderma Relat disord 2018;3(1):21-9.

[67] Chakravarty EF, Khanna D, Chung L. Pregnancy outcomes in systemic sclerosis, primary pulmonary hypertension, and sickle cell disease. Obs Gynecol 2008;111(4):927-34.

[68] Triggianese P, Conigliaro P, Chimenti MS, Barbato C, Greco E, Kroegler B, et al. Systemic sclerosis: Exploring the potential interplay between thyroid disorders and pregnancy outcome in an Italian cohort. Isr Med Assoc J 2017;19(8):473-7.

[69] Minier T, Nagy Z, Bálint Z, Farkas H, Radics J, Kumánovics G, et al. Construct validity evaluation of the European Scleroderma study group activity index, and investigation of possible new disease activity markers in systemic sclerosis. Rheumatology (Oxford) 2010;49(6):1133-45.

[70] Melsens K, De Keyser F, Decuman S, Piette Y, Vandecasteele E, Smith V. Disease activity indices in systemic sclerosis: a systematic literature review. Clin Exp Rheumatol 2016;34(5):186-92. Suppl 100.

[71] Valentini G, Iudici M, Walker UA, Jaeger VK, Baron M, Carreira P, et al. The European Scleroderma Trials and Research group (EUSTAR) task force for the development of revised activity criteria for systemic sclerosis: derivation and validation of a preliminarily revised EUSTAR activity index. Ann Rheum Dis 2017;76(1):270-6.

[72] Jennette JC, Falk RJ, Bacon PA, Basu N, Cid MC, Ferrario F, et al. revised International Chapel Hill consensus conference nomenclature of vasculitides. Arthritis Rheum 2012;65(1):1-11. 2013.

[73] Luqmani RA, Bacon PA, Moots RJ, Janssen BA, Pall A, Emery P, et al. Birmingham vasculitis activity score (BVAS) in systemic necrotizing vasculitis. QJM 1994;87(11):671-8.

[74] Exley AR, Bacon PA, Luqmani RA, Kitas GD, Gordon C, Savage CO, et al. Development and initial validation of the vasculitis damage index for the standardized clinical assessment of damage in the systemic vasculitides. Arthritis Rheum 1997:40(2):371-80.

[75] Tuin J, Sanders JS, de Joode AA, Stegeman CA. Pregnancy in women diagnosed with antineutrophil cytoplasmic antibody-associated vasculitis: outcome for the mother and the child. Arthritis Care Res 2012;64(4):539-45.

[76] Pagnoux C, Le Guern V, Goffinet F, Diot E, Limal N, Pannier E, et al. Pregnancies in systemic necrotizing vasculitides: report on 12 women and their 20 pregnancies. Rheumatology 2011;50(5):953-61.

[77] Koukoura O, Mantas N, Linardakis H, Hajiioannou J, Sifakis S. Successful term pregnancy in a patient with Wegener's granulomatosis: case report and literature review. Fertil Steril 2008;89(2). (457.e1-5).

[78] Lima F, Buchanan N, Froes L, Kerslake S, Khamashta MA, GRV Hughes. Pregnancy in granulomatous vasculitis. Ann Rheum Dis 1995;54(7):604-6.

[79] Auzary C, Le Thi Huong D, Wechsler B, Vauthier-Brouzes D, Piette JC. Pregnancy in patients with Wegener's granulomatosis: report of five cases in three women. Ann Rheum Dis 2000;59(10):800-4.

[80] Barry C, Davis S, Garrard P, Ferguson IT. Churg-strauss disease: deterioration in a 
twin pregnancy. Successful outcome following treatment with corticosteroids and cyclophosphamide. BJOG An Int J Obstet Gynaecol 1997;104(6):746-7.

[81] Silva F, Specks U, Sethi S, Irazabal MV, Fervenza FC. Successful pregnancy and delivery of a healthy Newborn despite transplacental transfer of antimyeloperoxidase antibodies from a Mother with microscopic polyangiitis. Am J Kidney Dis 2009;54(3):542-5.

[82] Alfhaily F, Watts R, Leather A. Wegener's granulomatosis occurring de novo during pregnancy. Clin Exp Rheumatol 2009;27(1):S86-8. Suppl 52.

[83] Kunjal R, Makary R, Poenariu A. Granulomatosis with Polyangiitis presenting as Pauci-Immune Crescentic Glomerulonephritis in pregnancy. Case Reports Nephrol 2016;2016:1-4.

[84] Gatto M, Iaccarino L, Canova M, Zen M, Nalotto L, Ramonda R, et al. Pregnancy and vasculitis: a systematic review of the literature. Autoimmun Rev 2012;11(6-7):A447-59.

[85] Machen L, Clowse MEB. Vasculitis and pregnancy. Rheum Dis Clin North Am 2017;43(2):239-47.

[86] Clowse MEB, Richeson RL, Pieper C, Merkel PA. Pregnancy outcomes among patients with vasculitis. Arthritis Care Res (Hoboken). 2013;65(8):1370-4.

[87] Weyand C, Goronzy J. Medium and large vessel vasculitis. N Engl J Med 2003;84(1):55-67.

[88] Comarmond C, Mirault T, Biard L, Nizard J, Lambert M, Wechsler B, et al. Takayasu arteritis and pregnancy. Arthritis Rheumatol 2015;67(12):3262-9.

[89] Alpay-Kanitez N, Omma A, Erer B, Artim-Esen B, Gül A, Inanç M, et al. Favourable pregnancy outcome in Takayasu arteritis: a single-Centre experience. Clin Exp Rheumatol 2015;33(2). Suppl 89. [S-7-10].

[90] Assad APL, Da Silva TF, Bonfa E, Pereira RMR. Maternal and neonatal outcomes in 89 patients with Takayasu Arteritis (TA): Comparison before and after the TA diagnosis. J Rheumatol 2015;42(10):1861-4.

[91] Tanaka H, Tanaka K, Kamiya C, Iwanaga N, Yoshimatsu J. Analysis of pregnancies in women with Takayasu arteritis: complication of Takayasu arteritis involving obstetric or cardiovascular events. J Obstet Gynaecol Res 2014;40(9):2031-6.

[92] Zhang Y, Li Y, Zhang J. Clinical analysis: 13 cases of pregnancy complicated with Takayasu arteritis. Ginekol Pol 2017;88(12):654-61.

[93] Kirshenbaum M, Simchen MJ. Pregnancy outcome in patients with Takayasu's arteritis: cohort study and review of the literature. J Matern Neonatal Med. 2017:1-7.

[94] Mandal D, Mandal S, Dattaray C, Banerjee D, Ghosh P, Ghosh A, et al. Takayasu arteritis in pregnancy: an analysis from eastern India. Arch Gynecol Obstet 2012;285(3):567-71.

[95] Suri V, Aggarwal N, Keepanasseril A, Chopra S, Vijayvergiya R, Jain S. Pregnancy and Takayasu arteritis: a single Centre experience from North India. J Obs Gynaecol Res 2010;36(3):519-24.

[96] Muratore F, Pazzola G, Soriano A, Pipitone N, Croci S, Bonacini M, et al. Unmet needs in the pathogenesis and treatment of vasculitides. Clin Rev Allergy Immunol 2018;54(2):244-60.

[97] Iskender C, Yasar O, Kaymak O, Yaman ST, Uygur D, Danisman N. Behcet's disease and pregnancy: a retrospective analysis of course of disease and pregnancy outcome. J Obstet Gynaecol Res 2014;40(6):1598-602.

[98] Noel N, Wechsler B, Nizard J, Costedoat-Chalumeau N, Boutin du LT, Dommergues M, et al. Behçet's disease and pregnancy. Arthritis Rheum 2013;65(9):2450-6.

[99] Xu C, Bao S. Behcet's disease and pregnancy-a case report and literature review. Am J Reprod Immunol 2017;77(1):e12530.

[100] Chen JS, Roberts CL, Simpson JM, March LM. Pregnancy outcomes in women with rare autoimmune diseases. Arthritis Rheumatol (Hoboken, NJ). 2015;67(12):3314-23.

[101] Jadaon J, Shushan A, Ezra Y, Sela HY, Ozcan C, Rojansky N. Behcet's disease and pregnancy. Acta Obs Gynecol Scand 2005;84:939-44.

[102] Komaba H, Takeda Y, Fukagawa M. Extensive deep vein thrombosis in a postpartum woman with Behçet's disease associated with nephrotic syndrome. Kidney Int 2007;71(1):6.

[103] Ben-Chetrit E. Behcet's syndrome and pregnancy: course of the disease and pregnancy outcome. Clin Exp Rheumatol 2014;32(4):S93-8. Suppl 84.

[104] Orgul G, Aktoz F, Beksac MS. Behcet's disease and pregnancy: what to expect? J Obstet Gynaecol 2018;38(2):185-8.

[105] Oka M. Effect of pregnancy on the onset and course of rheumatoid arthritis. Obstet Gynecol Surv 1954;9(2):180-1.

[106] Hargreaves ER. A survey of rheumatoid arthritis in West Cornwall; a report to the Empire Rheumatism Council. Ann Rheum Dis 1958;17(1):61-75.

[107] Smith WDWH. Pregnancy in rheumatoid arthritis. Acta Rheum Scand 1960(6):189-201.

[108] Morris WI. Pregnancy in rheumatoid arthritis and systemic lupus erythematosus. Aust N Z J Obstet Gynaecol 1969;9(3):136-44.

[109] Unger A, Kay A, Griffin AJ, Panayi GS. Disease activity and pregnancy associated alpha 2-glycoprotein in rheumatoid arthritis during pregnancy. BrMedJ (ClinResEd) 1983;286(0267-0623 (Print)):750-752. pm:6402232.

[110] Ostensen M, Aune B, Husby G. Effect of pregnancy and hormonal changes on the activity of rheumatoid arthritis. Scand J Rheumatol 1983;12(2):69-72.

[111] Østensen M, Husby G. A prospective clinical study of the effect of pregnancy on rheumatoid arthritis and ankylosing spondylitis. Arthritis Rheum 1983;26(9):1155-9.
[112] Nelson JL, Hughes KA, Smith AG, Nisperos BB, Branchaud AM, Hansen JA Maternal-Fetal Disparity in HLA Class II Alloantigens and the pregnancy-induced Amelioration of Rheumatoid Arthritis. N Engl J Med 1993;329(7):466-71.

[113] Quinn C, Mulpeter K, Casey EB, Feighery CF. Changes in levels of igm RF and $\alpha 2$ PAG correlate with increased disease activity in rheumatoid arthritis during the puerperium. Scand J Rheumatol 1993;22(6):273-9.

[114] Van Der Horst-Bruinsma IE, RRP De Vries, PDM De Buck, van Schendel PW, Breedveld FC, Schreuder GM, et al. Influence of HLA-class II incompatibility between mother and fetus on the development and course of rheumatoid arthritis of the mother. Ann Rheum Dis 1998;57(5):286-90.

[115] Barrett JH, Brennan P, Fiddler M, Silman A. Breast-feeding and postpartum relapse in women with rheumatoid and inflammatory arthritis. Arthritis Rheum 2000;43(5):1010-5.

[116] Brennan P, Barrett J, Fiddler M, Thomson W, Payton T, Silman A. Maternal-fetal HLA incompatibility and the course of inflammatory arthritis during pregnancy. J Rheumatol 2000;27(12):2843-8.

[117] Østensen M, Förger F, Nelson JL, Schuhmacher A, Hebisch G, Villiger PM. Pregnancy in patients with rheumatic disease: anti-inflammatory cytokines increase in pregnancy and decrease post partum. Ann Rheum Dis 2005;64(6):839-44.

[118] Förger F, Østensen M, Schumacher A, Villiger PM. Impact of pregnancy on health related quality of life evaluated prospectively in pregnant women with rheumatic diseases by the SF-36 health survey. Ann Rheum Dis 2005;64(10):1494-9.

[119] De Man YA, Bakker-Jonges LE, Dufour-Van Den Goorbergh CM, Tillemans SP, Hooijkaas H, Hazes JM, et al. Women with rheumatoid arthritis negative for anticyclic citrullinated peptide and rheumatoid factor are more likely to improve during pregnancy, whereas in autoantibody-positive women autoantibody levels are not influenced by pregnancy. Ann Rheum Dis 2010;69(2):420-3.

[120] Zrour SH, Boumiza R, Sakly N, Mannai R, Korbaa W, Younes M, et al. The impact of pregnancy on rheumatoid arthritis outcome: the role of maternofetal HLA class II disparity. Jt Bone Spine 2010;77(1):36-40.

[121] Förger F, Vallbracht I, Helmke K, Villiger PM, Østensen M. Pregnancy mediated improvement of rheumatoid arthritis. Swiss Med Wkly 2012;142.

[122] Quax RA, de Man YA, Koper JW, van Rossum EF, Willemsen SP, Lamberts SW, et al. Glucocorticoid receptor gene polymorphisms and disease activity during pregnancy and the postpartum period in rheumatoid arthritis. Arthritis Res Ther 2012;14(4):R183.

[123] Bondt A, Selman MHJ, Deelder AM, Hazes JM, Willemsen SP, Wuhrer M, et al. Association between galactosylation of immunoglobulin $\mathrm{G}$ and improvement of rheumatoid arthritis during pregnancy is independent of sialylation. J Proteome Res 2013;12(10):4522-31.

[124] Weix J, Häupl T, Raio L, Villiger PM, Förger F. The physiologic increase in expression of some type i IFN-inducible genes during pregnancy is not associated with improved disease activity in pregnant patients with rheumatoid arthritis. Transl Res 2013;161(6):505-12.

[125] De Steenwinkel FDO, Hokken-Koelega ACS, De Ridder MAJ, Hazes JMW, Dolhain RJEM. Rheumatoid arthritis during pregnancy and postnatal catch-up growth in the offspring. Arthritis Rheumatol 2014;66(7):1705-11.

[126] de Steenwinkel FDO, Hokken-Koelega ACS, Hazes JMW, Dolhain RJEM. Brief report: does medication use or disease activity during pregnancy in patients with rheumatoid arthritis affect bone density in their prepubertal offspring? Arthritis Rheumatol (Hoboken, NJ) 2014;66(3):533-7.

[127] Langen ES, Chakravarty EF, Liaquat M, El-Sayed YY, Druzin ML. High rate of preterm birth in pregnancies complicated by rheumatoid arthritis. Am J Perinatol 2014;31(1):9-13.

[128] Atta DS, Girbash EF, Abdelwahab SM, Abdeldayem HM, Tharwat I, Ghonaim R. Maternal cytokines and disease severity influence pregnancy outcomes in women with rheumatoid arthritis. J Matern Neonatal Med. 2016:1-6.

[129] Brouwer J, Laven JSE, Hazes JMW, Dolhain RJEM. Brief report: Miscarriages in female rheumatoid arthritis patients: Associations with serologic findings, disease activity, and antirheumatic drug treatment. Arthritis Rheumatol 2015;67(7):1738-43.

[130] Ince-Askan H, Hazes JMW, Dolhain RJEM. Is disease activity in Rheumatoid arthritis during pregnancy and after delivery predictive for disease activity in a subsequent pregnancy? J Rheumatol 2016;43(1):22-5.

[131] Tham M, Schlör GR, Yerly D, Mueller C, Surbek D, Villiger PM, et al. Reduced proinflammatory profile of $\gamma \delta \mathrm{T}$ cells in pregnant patients with rheumatoid arthritis. Arthritis Res Ther 2016;18(1).

[132] Ince-Askan H, Hazes JMW, Dolhain RJEM. Identifying clinical factors associated with low disease activity and remission of Rheumatoid Arthritis during pregnancy. Arthritis Care Res (Hoboken) 2017;69(9):1297-303.

[133] de Steenwinkel FDO, Dolhain RJEM, Hazes JMW, Hokken-Koelega ACS. Does prednisone use or disease activity in pregnant women with rheumatoid arthritis influence the body composition of their offspring? Reprod Toxicol 2017:71:118-23.

[134] Bondt A, Hafkenscheid L, Falck D, Kuijper TM, Rombouts Y, Hazes JMW, et al ACPA IgG galactosylation associates with disease activity in pregnant patients with rheumatoid arthritis. Ann Rheum Dis 2018;77(8):1130-6. (Aug, annrheumdis-2018-212946). 